\title{
Facilitating Knowledge Visualisation as Communication and Knowledge Transfer Mechanism in Postgraduate Learning
}

\author{
Judy van Biljon ${ }^{1(\bowtie)}$ and Karen Renaud ${ }^{1,2}$ \\ ${ }^{1}$ School of Computing, University of South Africa, Pretoria, South Africa \\ vbilija@unisa.ac.za \\ 2 School of Computing Science, University of Glasgow, Glasgow, Scotland, UK
}

\begin{abstract}
Advances in technology and subsequent access to inexpensive software have made visualisation, as a method of knowledge creation and transfer, more accessible. Visualisations have been used to support knowledge representation and transfer in teaching but the focus has primarily been on creating visualisations for learner consumption. The idea of students becoming active participants in producing visualisations, as part of knowledge creation and learning, has largely been overlooked.

The study reported here investigated the use of visualisation for summarising knowledge at postgraduate level. The student's need to assimilate and organise knowledge is an important part of their learning. We suggest that it would be useful for students to learn how to produce knowledge visualisations as part of this activity. The production is an act of knowledge creation, which can improve their comprehension of the research literature.

Producing visualisations is not necessarily straightforward and it is therefore advisable to scaffold the process. We propose a faded-struts learning process that gradually removes scaffolding as the learner masters the principles and becomes more adept. The contribution of this research is to present the idea of providing worked examples and faded examples to support postgraduate learning. This helps postgraduates to craft knowledge visualisations so that they can slowly become more proficient and independent. Due to the ubiquity of mobile devices we propose providing this support on these devices, incorporating their unique constraints and affordances in our learning process.

This is essentially a proof of concept paper, suggesting how the idea could be realised. Further work is necessary to test the idea with students and to extend the repertoire of mobile learning (m-learning) visualisation tasks.
\end{abstract}

Keywords: Knowledge visualisation - Knowledge transfer - Post graduate learning $\cdot$ Faded-Struts approach

\section{Introduction}

Critical factors for the successful adoption of m-learning include interactivity, coordination, negotiation and communication, organization of material and mobility. Mobility is central to the intersection of these factors, supporting dialectic relations and 
convergences between the contextual, semiotic, technological and pedagogical dimensions of m-learning (Petit and Santos 2014). This calls for a reflection on how teaching and learning content presentation can be optimized to exploit mobility in general, and the role of visualisation in particular, the focus of this paper.

Visualisations have a powerful capacity to improve inter-personal communication and interaction, but this can only be realized if the visualisation is appropriate and effective (Burkhard 2005). Our proposal is that postgraduates should include visualisations in their dissertations. There are two benefits of doing this. The first is that visualisations will improve the dissertation by transferring knowledge more effectively. The second is that the production of visualisation, in and of itself, can help students to conceptualise and comprehend the knowledge they are assimilating (Laseau 2000).

If visualisations are to mediate in the postgraduate context it is necessary to foster the nuanced understanding required to deploy visualisations appropriately and effectively. This is especially true in the mobile context where people need to steer clear of deployment and crafting risks (Bresciani and Eppler 2008). Providing support is particularly important in the m-learning environment with its unique constraints and affordances. Various authors have proposed information visualisation guidelines that could help but knowledge visualisation has received very little attention. The target group for this study is postgraduate students in an open distance-learning environment in South Africa.

Sharples et al. (2010) argue that the convergence of learning and mobile technologies allows people to learn in a life-long fashion, no longer constrained by classroom-based attendance. This applies particularly in this case since many of these students are employed full time and spend time traveling to work on public transport where the only computing devices available to support learning are mobile devices (smart phones and tablets). Being able to use mobile devices to facilitate the knowledge visualisation learning process can extend their learning time and opportunities.

Traxler (2009) reviews the state of play in m-learning, and reports on its use primarily in supporting children or undergraduate students. Wishart (2009) reports on the use of mobile technology to support teacher training. We argue that there is potential for postgraduates, too, to benefit from the availability and affordances of mobile devices in an m-learning context.

The nature of a postgraduate's "learning" is different from that of undergraduates in some very profound ways. According to James (1998), postgraduates have to demonstrate that they understand related research, can relate their own work to such research and can interact vigorously with the content. Crucially for the svisualisation context, they have to be able to show that they can organize principles and integrate ideas. This is usually achieved by writing about the work coherently, and presenting an argument that demonstrates understanding. There is another way to demonstrate this: by crafting a visualisation to demonstrate such understanding, engagement and ability to synthesize (Chen et al. 2009). 
A side benefit might even be that an improved understanding emerges from this activity (Laseau, 2000). In Sect. 2 we establish the nature of data, information and knowledge, and visualisation thereof. We discuss learning styles and how learners can be supported in learning to visualise. Finally, we present the constraints of the mobile environment as a mechanism for supporting knowledge visualisation in m-learning. We then suggest the building blocks for knowledge visualisation m-learning. We propose a faded-struts learning process that moves from worked examples, to faded worked examples, to active production, supported by peers, in Sect. 3. Section 4 walks through an example of the proposed learning process. Section 5 concludes.

\section{Background Literature}

\subsection{Knowledge, Information and Data Visualisation}

When considering knowledge visualisation, we need to establish a shared understanding of the meaning of the terms data, information and knowledge. For the purpose of this paper data, information and knowledge are described as follows (Chen et al. 2009):

- Data - facts, concepts, or instructions suitable for interpretation or processing by humans or by software.

- Information- data with the associated meaning assigned by humans suitable for visualisation to encourage the revealing of patterns or insights into the data.

- Knowledge- information, together with understanding, awareness, or familiarity acquired through interpretation and application of information.

According to these definitions processed data becomes information and interpreted information becomes knowledge. Each level of processing adds bias due to the subjective selection of processing procedures. The only way to manage the accountability of the process is to state the assumptions and take cognisance of the constraints at each step of the process (Muller et al. 2012).

In the context of learning, visualisation is expected to lead to new insights. An individual's sense-making, the progression from data to gaining understanding and insight, is fundamental to knowledge acquisition and transfer. We therefore find it useful to revisit the differences between data, information and knowledge visualisations as illustrated by van Biljon and Renaud (2015) in Table 1.

Eppler and Burkhard (2007) structure the visualisation formats into seven main groups, namely: structured text/tables, mental (non-material) visualisation and visual storytelling, heuristic sketches, conceptual diagrams/concept maps, visual metaphors, knowledge maps, and graphic interactive environments. Taking cognisance of the variety of visualisation formats is important towards grasping the potential for knowledge creation, representation and transfer. The narrow perception, that visualisation encapsulates only the use of pictures and diagrams, is a limiting factor for its potential use and usefulness. 
Table 1. Differences between data, knowledge and information visualisation (van Biljon and Renaud 2015)

\begin{tabular}{|c|c|c|c|}
\hline & Data Visualisation & Information Visualisation & Knowledge Visualisation \\
\hline Goal & $\begin{array}{l}\text { Support Exploration of } \\
\text { data using graphical } \\
\text { metaphors }\end{array}$ & $\begin{array}{l}\text { Support Exploration of Large } \\
\text { Amounts of Data \& Knowledge } \\
\text { Creation }\end{array}$ & $\begin{array}{l}\text { Ease Knowledge Transfer; Creation } \\
\text { of New Knowledge }\end{array}$ \\
\hline Benefit & $\begin{array}{l}\text { Make data mining } \\
\text { available to everyone, } \\
\text { not just experts }\end{array}$ & $\begin{array}{l}\text { Identification of patterns, } \\
\text { exploration of large data sets }\end{array}$ & $\begin{array}{l}\text { Augmenting knowledge transfer } \\
\text { between individuals; } \\
\text { communicating knowledge }\end{array}$ \\
\hline \multirow[t]{2}{*}{ Content } & A large volume of data & Explicit data such as facts and & Experiences, insights, instructions, \\
\hline & $\begin{array}{l}\text { which needs to have } \\
\text { meaning identified }\end{array}$ & numbers & assumptions \\
\hline $\begin{array}{l}\text { Answers } \\
\text { Question }\end{array}$ & Where & What & Why, Who, How \\
\hline Recipients & Data miners & Data Explorer, Pattern Spotter & Knowledge Workers \\
\hline Influence & Data mining & Data analysis, Data exploration & Knowledge Transfer \\
\hline Example & $\begin{array}{l}\text { Pie chart representing } \\
\text { of visualisation's } \\
\text { distribution in a set of } \\
\text { masters dissertations } \\
\begin{array}{c}\text { Findines } \\
3 \times\end{array}\end{array}$ & 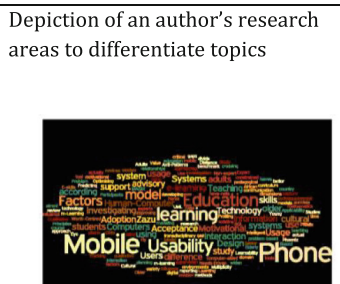 & $\begin{array}{l}\text { Representation of the relationship } \\
\text { between data, information and } \\
\text { knowledge. }\end{array}$ \\
\hline
\end{tabular}

\subsection{Learning Styles and Learning How to Visualize}

Cognitive learning styles have been defined as "the information processing habits of individual learners" (Keefe, 1991). While individuals are different in their ways of seeking and processing information, cognitive styles serve as relatively stable indicators of how learners perceive and interpret information, and respond to learning environments (Wolfe \& Johnson 1995). Learning styles have been categorised in terms of visual, kinaesthetic and aural modal preferences (Fleming 1995) and that may well impact the learning that will result from any activity. One study revealed that students' cognitive styles were not significantly correlated with their attitudes and preference for instructional delivery modes (Oh and Lim 2005). However, other factors, such as learners' attitudes, previous online learning experience and computer competency were indeed significantly correlated with students' learning outcomes and attitudes toward online instruction. A comprehensive discussion of learning styles is beyond the scope of this study. However, knowledge visualisation can be considered a complementary 
activity where some may benefit more than others but individual learning styles should not exclude any individual from benefitting.

Kirshner and Merriënboer (2008) describe learning in terms of the development of new schemata, a structured chunk of related knowledge (Robins et al. 2003) and the moving on to their establishment and maintenance. As these schemata become well established it becomes easy for the learner to match them to new situations. Before they are established the learner has to use valuable working memory to make sense of new situations and therefore becomes easily overwhelmed by too many new concepts (Cowan 2012). This suggests that the introduction of new material has to be managed very carefully not to overwhelm the learner. Visualisation, and the principles underlying visualisation, is no different; the limitations of mobile devices may even complicate the learning if not given due consideration. We therefore have to introduce new knowledge in such a way that learners can apply existing knowledge in a novel setting, acquiring new knowledge by building on existing knowledge (Al-Shuaily 2013). New material has to be introduced slowly and mindfully (Larkin 1989). Throwing a learner into the deep end by asking them to construct visualisations, without their having mentally constructed the required schemata, forces them into engaging in a trial and error process, and not really learning basic principles during the process. This is depicted in Fig. 1. We wish to provide enough scaffolding and support so that it is not necessary for the learner to go down the "trial and error" route in order to cope.

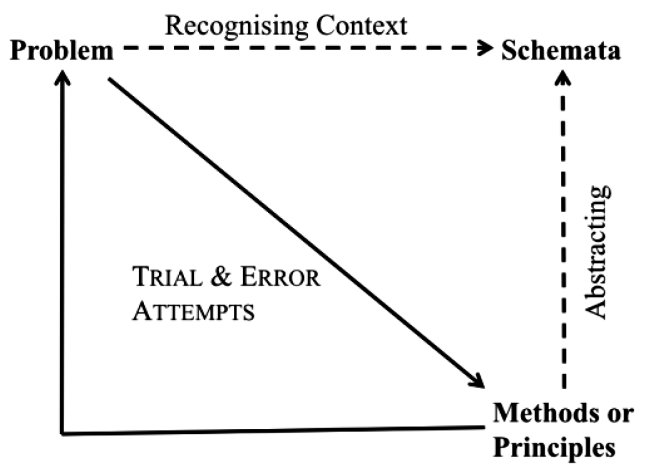

Fig. 1. Knowledge assimilation approach (Al-Shuaily 2013) (p.233)

How have people been supported in creating visualisations in the past? Mostly by the provision of guidelines. Kelleher and Wagener (2011) provided guidelines for effective data visualisation in scientific publications. Forsell and Johansson (2010) proposed a heuristic set for the evaluation of information visualisations. Engelbrecht, Botha and Alberts (2014) also provide information visualisation guidelines. Despite a number of publications offering guidelines, evaluation guidelines remain a key research challenge within the international Information Visualisation community (Forsell and Johansson 2010). Moreover, the deployment of knowledge visualisation in an m-learning context has not been researched in any depth. Our proposal is not merely a 
new approach but the first for supporting the production of knowledge visualisations on a mobile platform. In coming up with learning support in this context we first consider the unique constraints of the mobile environment.

\subsection{Mobile Learning Constraints}

Mobile devices, as a newly emergent and ubiquitous display context, have specific device and infrastructure constraints that have to be considered during the production of m-learning initiatives. Mobile devices, as a learning tool, have some significant differences from the usual classroom environment:

- Their context of use is variable. A classroom is a strictly controlled environment with the presence of a teacher or assistant taken for granted, and where other learners surround a learner. A mobile learner's context is unpredictable and unknowable. It could be noisy, quiet, solitary or busy. A learner could easily be interrupted while busy learning, by a call coming in. The device has to maintain state seamlessly; allowing re-establishment of context once the activity is resumed.

- Connectivity, with servers or other required support structures, cannot be guaranteed. Despite the incredibly speedy laying down of infrastructures by mobile service providers some users still experience periods of poor or no connectivity. This is still a fact of life for mobile users in developing countries. This intermittent connectivity means that the mobile learner cannot rely on being able to access servers so that the m-learning package has to be designed to continue to function when not connected.

- The memory on the device is constrained. Memory, data storage devices, has become cheaper and more plentiful year by year since Moore proposed his law (Schaller 1997) predicting this development. It does not apply to mobile devices yet, though. Memory is constrained, as is processing power, mainly because of limited battery power. Moreover, the write time is relatively expensive, in the context of a battery-powered device, so that this has to be constrained if the battery is not to be drained too fast.

- Power is the biggest challenge. The device has been designed to spend most of its time sleeping. Any sustained use drains the battery and might render the device useless for its core purpose, communicating with other people.

- The mobile phone has a new development environment that is limited in terms of debugging tools and available libraries. This makes it a challenging environment to develop for.

- The screen is small, as compared to a desktop device. The kinds of techniques used by user interface developers on a large screen are not suitable. For example, overlapping windows cannot be used, nor can multiple buttons. Menu hierarchies have to be limited, since they can easily get too big for the screen. This essentially means that decisions have to be made about what can be shown, and what needs to be left off the screen.

The power and scope of these devices is developing daily so many of these challenges may well diminish as time goes by. The constraints caused by the size of the 
screen, however, can be expected to endure since it is determined by the size of an average pocket. Any visualisation has to take this limited space into consideration.

\section{Proposed Learning Support: The Faded-Struts Approach}

The research question we consider is "How can the production of knowledge visualisations be supported in an m-learning context?" The first step is to model the visualisation production process, then to consider how best to support postgraduates learning on how to produce visualisations.

One task that is engaged in by all postgraduates is the synthesis and summarization of a body of knowledge in a particular area. They are all required to read a number of academic papers and to produce a coherent story that interleaves these while rigorously citing the sources. Many students will subsequently summarize these in tabular format. Tabularisation is a mechanism to support the selection, combination and integrations of information from different sources in order to provide a balanced representation of the core knowledge available to the person on the topic under summarisation. We therefore focus on this summarization process, in launching a discourse on the use of visualisation in m-learning.

To model the visualisation of knowledge in this context we adapt the knowledge management process suggested by Zeiller (2005). He suggests a set of building blocks making up the knowledge management process. We have revised his building blocks to support developing the knowledge visualisation development process, incorporating the insights we gained from the literature review (Fig. 2).

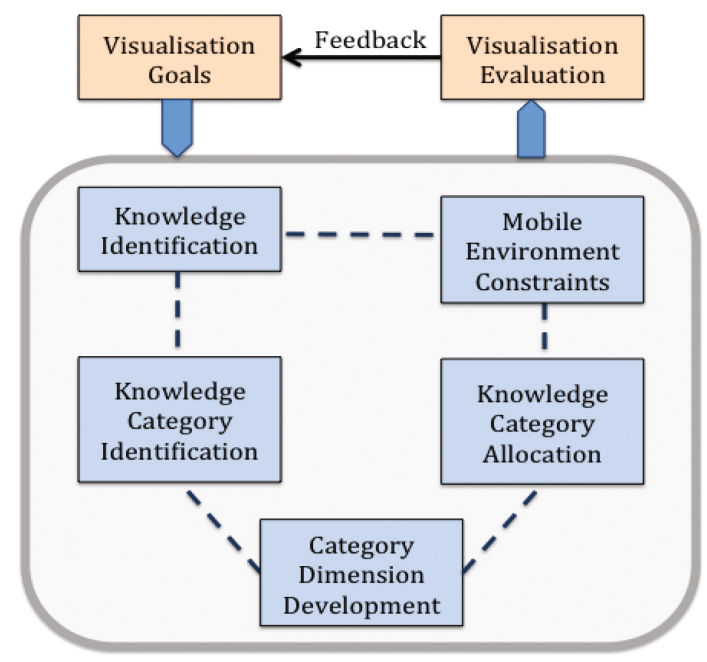

Fig. 2. Knowledge visualisation building blocks (adapted from Song (2014)) 
The stages involved in crafting the visualisation are:

1. Knowledge Identification: This is driven by the given task, the available knowledge resources and the width and depth of the expected outcome of the postgraduate student's task.

2. Knowledge Category Identification: This is the result of an abstraction the student carries out: it demonstrates an ability to rise above minutiae, to focus on getting core information and abstract principles from the individual research the student has read.

3. Category Dimension Development: This leads on from the previous activities. Having fixed on a set of description categories, the student now expands these categories into individual descriptors/dimensions.

4. Knowledge Category Allocation: The student now mines the literature to allocate individual research ideas, papers or items of work to the intersections between the descriptive categories.

5. Mobile Device Constraints: These will take the form of listen constraints and considerations, based on the discussion in Sect. 2.3.

The next step is to consider how learners can be supported through this process. We propose using a variation of the faded-examples learning process proposed by Song (2014). This adapted process ought to teach learners how to produce visualisations, in this case tables, depicting an overview of the literature they have researched. Song points out that apprenticeship is the gold standard of learning. The idea is that learners work through example after example, supervised by the ever-present master, until they assimilate enough experience to start working independently. The master removes the scaffolding of their assistance slowly as the learner demonstrates the ability to work independently (Lave and Wenger 1991).

This one-to-one apprenticeship is no longer feasible, but we can use the principles thereof to develop a slow and incremental learning process, similar to the approach proposed by Song (2014): examples, followed by faded examples (some support removed) and finally a peer-review process (Fig. 3). This fosters the slow and incremental development of the schemata, and ensures that the learner does not become overwhelmed during the learning process.

The faded-struts process starts with worked examples, a number of them, as suggested by Atkinson et al. (2000). The next step comprises faded examples, as suggested by Renkl and Atkinson (2003). Here some of the supports (struts) are removed, and the learner fills in the blanks, as it were. Song (2014) then suggests two more stages, guided discovery and minimal guidance. Instead, we propose that learners start interacting with each other, since the best way to learn is by teaching others. The skills being taught by Song's process are far simpler than knowledge visualisation and we do not believe that support can ever be withdrawn completely. Hence we propose moving from faded examples to peer review, providing minimal yet significant social support as learning continues and skills develop. The constant presence of the master is replaced by peer support as the learner starts to work independently. 


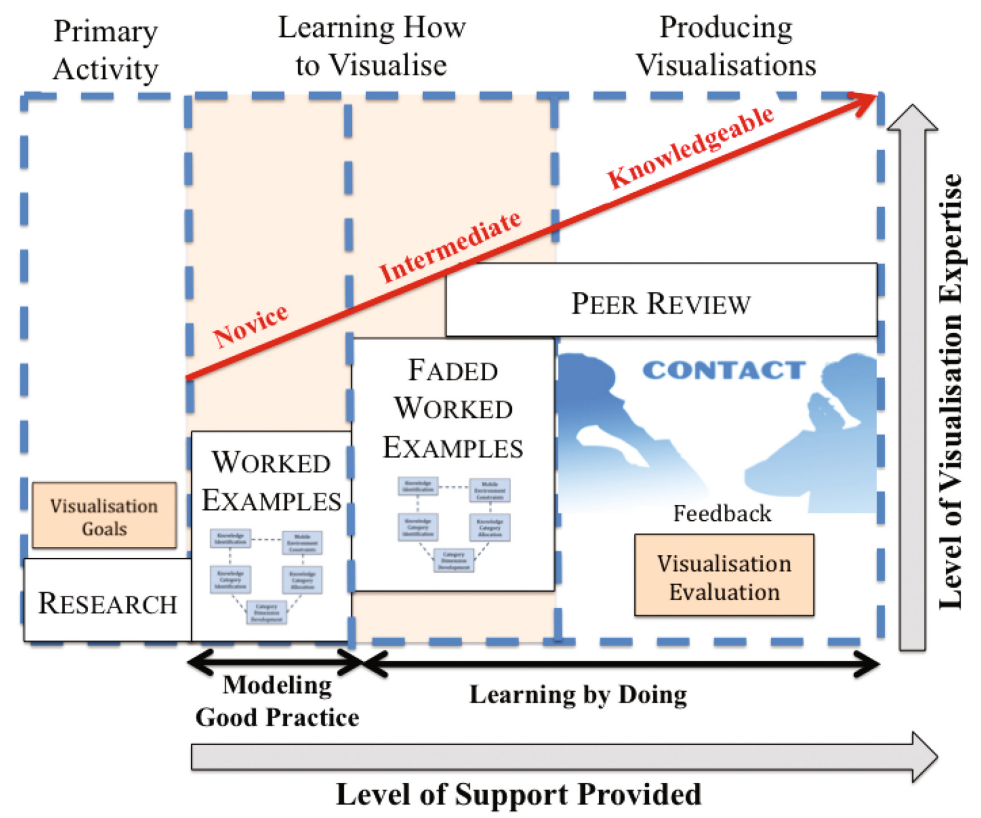

Fig. 3. Teaching postgraduates to visualise using a faded-struts approach adapted from (Song 2014)

Limitations. There are known risks to using knowledge visualisation (Bresciani and Eppler 2008). The risks could be both designer- and user-induced and relate to cognitive, emotional and social human aspects of the communication process. These can be exacerbated by the known m-learning constraints as noted in Sect. 2.3. By providing a stepped example-driven development process we attempt to minimise the risks and m-learning constraints.

\section{Proof of Concept Example of the Faded-Struts Approach}

One of the things all postgraduates are required to do is to gather information about a specific topic and then to provide a synthesis thereof (Golding et al. 2014; James 1998; Mullins and Kiley 2002). This is a time-consuming process and, despite the availability of similarity checking tools, plagiarism remains a concern. Provision of such a synthesis in a visual format, in this case in tabular format, is often particularly helpful. Yet we cannot expect students to know how to do this automatically. Hence, supporting the synthesis task on a mobile device, helping people to produce such a visualisation, would be valuable. We now step through this particular task in order to demonstrate the proposed knowledge-visualisation facilitated synthesis process. 


\begin{tabular}{|l|l|l|}
\hline Author(s) & Focus & Source \\
\hline Brown \& Mbati & Myths and opportunities & http://hdl.handle.net/10500/18589 \\
\hline $\begin{array}{l}\text { Chipangura, van } \\
\text { Biljon \& Botha }\end{array}$ & $\begin{array}{l}\text { Mobile-centric teaching and } \\
\text { learning }\end{array}$ & $\begin{array}{l}\text { http://researchspace.csir.co.za/dspace/bitstr } \\
\text { eam/10204/7731/1/Botha2_2013.pdf }\end{array}$ \\
\hline Koole & $\begin{array}{l}\text { Pedagogical issues of } \\
\text { information overload, } \\
\text { knowledge navigation, and } \\
\text { collaboration }\end{array}$ & $\begin{array}{l}\text { https://www.jisc.ac.uk/full-guide/mobile- } \\
\text { learning }\end{array}$ \\
\hline Kukulska-Hulme & $\begin{array}{l}\text { Learner attributes, skills and } \\
\text { competences }\end{array}$ & http://www.ifets.info/journals/13_4/2.pdf \\
\hline Sharples & $\begin{array}{l}\text { Contexts, Curricula, Cultures, } \\
\text { Ethics, Tools, Learning } \\
\text { activity, Access to } \\
\text { information and people. }\end{array}$ & $\begin{array}{l}\text { https://www.google.co.za/webhp?sourceid=c } \\
\text { hrome-instant\&ion=1\&espv=2\&ie=UTF- } \\
\text { 8\#q=sharples\%20small\%20design\%20big\%2 } \\
\text { 0issues }\end{array}$ \\
\hline
\end{tabular}

Fig. 4. Identifying sources from the Literature

\subsection{Worked Example}

Consider that a postgraduate student has the task of reviewing the literature for m-learning constraints in order to produce a synthesis thereof. The building blocks in Fig. 2 would be traversed as follows:

1. Knowledge Identification: The student searches for relevant literature and reads it in order to understand the current state of play. He or she now identifies the set of papers and other sources that need to be included in the synthesis.

2. Knowledge Category Identification: The knowledge can be categorised in a number of different ways, but as to start off the student is expected to use at least the following categories as columns (1) author(s), (2) focus and (3) source. Figure 5 shows a selection from the data capturing on the topic of mobile learning constraints.

\begin{tabular}{|l|l|l|}
\hline Focus & Author(s) & Source \\
\hline \multirow{3}{*}{ Technological } & Chipangura, van & http://researchspace.csir.co.za/dspace/bitstream/10204/7731/1/ \\
& Biljon \& Botha & Botha2_2013.pdf \\
\cline { 2 - 3 } & Brown \& Mbati & http://hdl.handle.net/10500/18589 \\
\hline \multirow{2}{*}{ Social } & Sharples & https://www.google.co.za/webhp?sourceid=chrome- \\
& & instant\&ion=1\&espv=2\&ie=UTF- \\
& & 8\#q=sharples\%20small\%20design\%20big\%20issues \\
\hline \multirow{2}{*}{ Learner } & Petit \& Santos & http://link.springer.com/chapter/10.1007\%2F978-3-319-13416- \\
& & 1_1\#page-1 \\
\cline { 2 - 3 } & Kukulska-Hulme & http://www.ifets.info/journals/13_4/2.pdf \\
\hline
\end{tabular}

Fig. 5. Structured according to m-learning constraint categories

3. Category Dimension Development: The previous step is intended to develop a more nuanced understanding of the task. Students should now be made aware of the fact that the constraints highlight particular aspects of the literature that describe the area. This step now takes them further to show how the literature can be organised in different ways. The previous step was generic, and probably applicable to any 
research area. This step now specialises the synthesis for the particular research domain.

During this phase a new table is created with the categories selected according to the specific domain area: m-learning constraints. In this case Koole's Frame model (2009) was selected, with the technological (device), the social and learner aspects as the three fundamental and overlapping sections. Columns are reorganised to ease the ordering of the dimensions (rows) as depicted in Fig. 5. The sources are the links to where the resource was found and the citation in the correct format is only extracted later.

4. Knowledge Category Allocation: there is an intersection between each of the aspects of m-learning and the constraints. During this stage the learner allocates particular papers to each intersection. The papers are organised chronologically to depict developments over time. For example, connectivity was identified as a constraint in 2002 (Sharples et al. 2002) this is mentioned by Brown and Mbati (2015) as an issue in the developing country context and hence it is retained as a constraint (Fig. 6).

\begin{tabular}{|c|c|c|c|}
\hline & \multicolumn{3}{|c|}{ M-Learning Constraints } \\
\hline & Connectivity & Device & Cost \\
\hline Technological & $\begin{array}{l}\text { Sharples et al. (2002, } \\
\text { 2007) }\end{array}$ & Chipangura et al. (2013) & Chipangura et al. (2012) \\
\hline & Brown \& Mbati (2015) & Traxler (2009) & Brown \& Mbati (2015) \\
\hline
\end{tabular}

Fig. 6. Refined m-learning constraints

This example was launched using the basic and inexpensive Summary Pro App on an iPad. The App has two windows, a resource window and summary window. Appropriate information is selected in the resource window (displaying a Web page or other online source) and dragged to the summary window to build a editable collection of items as depicted in Fig. 7. The App allows the user to create an electronic file (containing all the information) which automatically includes the online references. This constitutes the "Knowledge Identification" building block in Fig. 2. The information in that file can then be used to create the tables (visualisations), continuing with the subsequent knowledge visualisation building blocks (Fig. 2).

5. Mobile Device Constraints: A mobile device was used to carry out the time-consuming task of collecting and tagging that information and saving the related source, with the focus where appropriate. In the Summary Pro App items can be saved as an electronic file which automatically includes the online references. Creating a table is fundamental to the principles of a mindful literature gathering strategy and expecting students to continually keep track of the sources emphasises ethical research. The App does not provide further support towards structuring the list of information sources into a table and it might be worth investigating the development of such an App in the future. Any other App could be used to create the table in Fig. 4 but, given mobile device constraints in switching between windows, this remains a clunky process. 


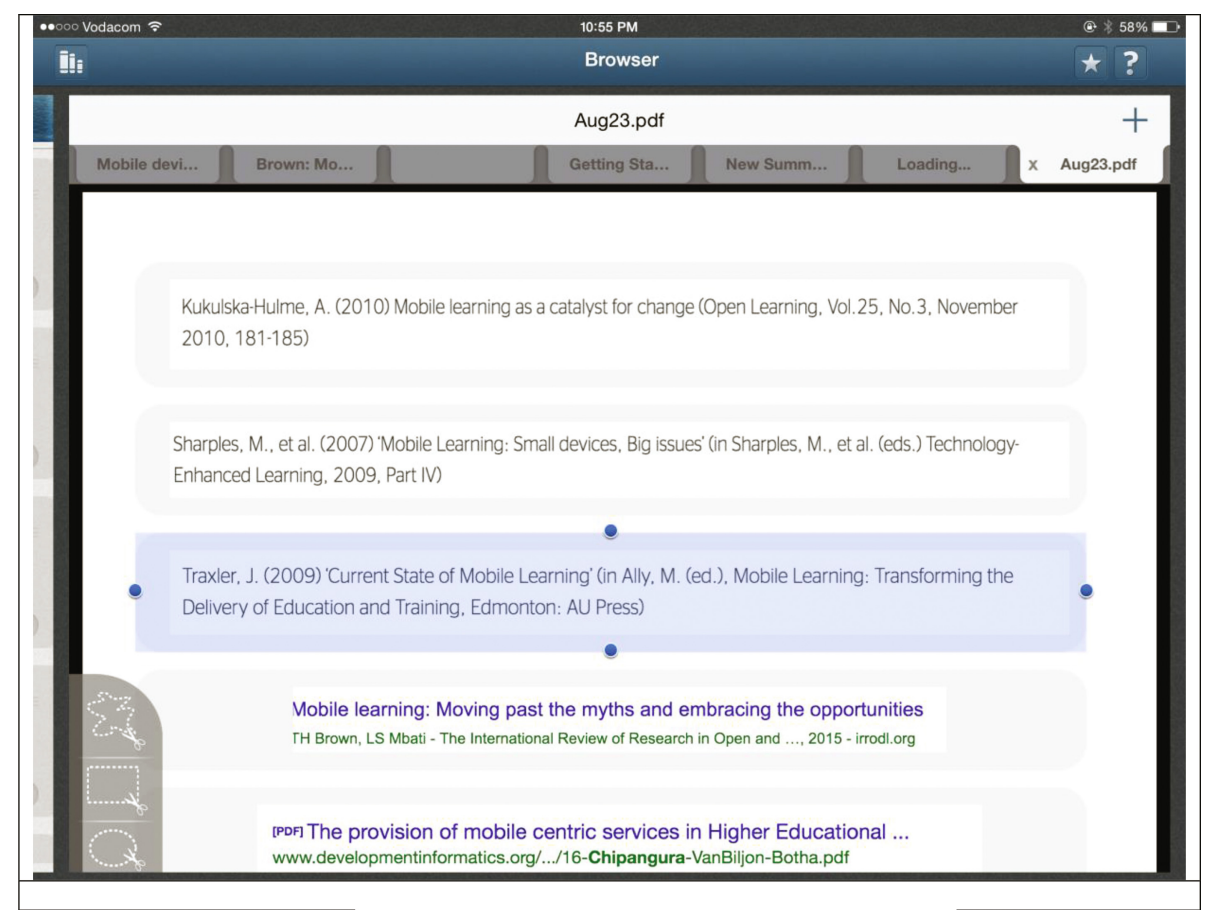

Fig. 7. Sources selected using the Mobile App

\subsection{Faded Example}

In the faded examples the students have to become more active in the learning process. The starting categories of author, focus and source would remain the same for the first table. Students would be given some dimensions of the second table and then be asked to add more themselves. An example follows.

Consider that a postgraduate student has been reviewing the literature on m-learning assessment. He/she now has to produce a summary of the literature. The building blocks would be traversed as follows:

1. Knowledge Identification: The student undertakes a search for all relevant papers.

2. Knowledge Category Identification: The first three categories are always the author, article focus and source. So the student sorts all the relevant papers into these three categories.

\section{Category Dimension Development:}

- The dimensions could now be expanded into: efficiency, e.g. time, cost and effort, and rigour

- More dimensions to be added by the student researcher. 
4. Knowledge Category Allocation: There should be an intersection between each kind of assessment and the learner's category dimensions. For example, the efficiency of multiple-choice assessment compared to the efficiency of essays, both submitted online. During this stage the learner allocates research publications to each intersection. The summary serves to show how well the learner understands the relevant literature.

The idea is that a number of these faded examples will be worked through before the student is expected to do the visualisation independently.

\subsection{Peer Review}

M-learning is advocated as supporting the social construction of knowledge amongst learners by enhancing their critical, creative, collaborative and communicative engagement within the knowledge application sites (Cobcroft et al. 2006). Brown (2005) emphasises the role of communication and interaction as critical success factors in the learning process. During this phase the visualisation can be shared with peers to obtain feedback so as to improve the visualisation.

\subsection{Discussion and Future Work}

This paper proposes a process to support postgraduate students to develop visualisations, in order to ease knowledge communication. The literature survey was selected as an exemplar research task with structured text (tables) as visualisation choice. The mobile App used to support summarisation, namely Summary Pro (iOS), combines online searching functionality with the functionality to copy and paste information items and save that in an electronic format together with the relevant links. Further investigation and possibly bespoke development will be pursued in order to provide adequate, free Apps to support knowledge visualisation as a tool for postgraduate students.

This is but one possibility for using visualisation in research reporting. Research flow diagrams are another task where the faded-struts concept is relevant. The App we used for the tabular synthesis but a different kind of App would be needed for creating a research-flow diagram.

The fact that visualisation software packages are visualisation-specific complicates the use of visualisation. On the other hand, the proliferation of mobile Apps suggests that this is a minor issue and unlikely to prevent this kind of m-learning approach.

\section{Conclusions}

Data, information and knowledge visualisations have an under-utilized yet powerful ability to support communication and interaction in m-learning. Given the barriers and pitfalls to developing successful knowledge visualisations for mobile phones it is easy to understand why visualisations have, thus far, been the domain of the visualisation 
experts. However, the improved accessibility to visualisation software, the ubiquity of mobile devices and the clear pedagogical value support our argument that it is time to involve students on creating knowledge visualisations and that is the rationale for this study.

Advances in technology and access to software have made visualisation, as a method of knowledge creation and transfer, accessible to anyone with access to a standard computing device. The progress has been in developing visualising knowledge for consumption by the learner, i.e. for teaching. The novelty of this paper lies in the focus on learners creating knowledge visualisation rather than simply consuming them. The proposed process relies on a wider definition of visualisation which includes structured text as a form of visualisation. Besides the intrinsic value of engaging the students in creating the visualisation there are also the potential benefits of collaboration, knowledge transfer and sharing.

The contribution of this research is to present the idea of creating knowledge visualisation by students and provide worked examples and faded examples as proof of concept on how to implement the idea. Further work is necessary to test the idea with students and extend the repertoire of m-learning visualisation tasks.

\section{References}

Al-Shuaily, H.: SQL pattern design, development \& evaluation of its efficacy Doctoral dissertation, University of Glasgow (2013)

Atkinson, R.K., Derry, S.J., Renkl, A., Wortham, D.: Learning from examples: instructional principles from the worked examples research. Rev. Educ. Res. 70(2), 181-214 (2000)

Bresciani, S., Eppler, M.J.: A classification of disadvantages associated with graphic representations of information. ICA Working Paper 1/2008, The Risks of Visualisation, pp. 1-22 (2008)

Brown, T.H.: Towards a model for m-learning in Africa. Int. J. e-learn. 4(3), 299-315 (2005)

Brown, T.H., Mbati, L.S.: Mobile-Learning: moving past the myths and embracing the opportunities. Int. Rev. Res. Open Distrib. Learn. 16(2), 115-135 (2015)

Burkhard, R.A.: Towards a framework and a model for knowledge visualisation: synergies between information and knowledge visualisation. Knowl. Inf. Visualisation 3426, 238-255 (2005)

Chen, M., Ebert, D., Hagen, H., Laramee, R.S., Liere, R.: Data, Information, and Knowledge in Visualisation. In: Visualisation viewpoints (Vol. January/February 2009), pp. 12-19. IEEE Computer Society (2009)

Chipangura, B., van Biljon, J.A., Botha, A.: Towards a mobile centric framework for inclusive sustainable interactions. Progressio 34(3), 161-182 (2012)

Chipangura, B., van Biljon, J., Botha, A.: Evaluating mobile centric information access and interaction compatibility for learning websites. In: Pan African International Conference on Information Science, Computing and Telecommunication (2013), pp. 218-222, Zambia, 2013. http://www.meraka.org.za/icast2013/ICAST2013_proceedings.pdf

Cobcroft, R.1.S., Towers, S., Smith, J., Bruns, A.: Mobile learning in review: Opportunities and challenges for learners, teachers, and institutions. In: Proceedings of 2006 Conference on Online Learning and Teaching (OLT) (2006)

Cowan, N.: Working memory capacity. Psychology Press, Hove (2012) 
Engelbrecht, L., Botha, A., Alberts, R.: Information visualisation view design: principles and guidelines. In: Proceedings of the International Conference on Computer Science, Computer Engineering, and Social Media, Thessaloniki, Greece (2014)

Eppler, M.J., Burkhard, R.A.: Visual representations in knowledge management: framework and cases. J. Knowl. Manage. 11(4), 112-122 (2007)

Fleming, N.D.: I'm different; not dumb. Modes of presentation (VARK) in the tertiary classroom. Research and development in higher education. In: Proceedings of the 1995 Annual Conference of the Higher Education and Research Development Society of Australasia (HERDSA), vol. 18, pp. 308 - 313 (1995)

Forsell, C., Johansson, J.: An heuristic set for evaluation in information visualisation. In: International Conference on Advanced Visual Interfaces- AVI 2010, Rome, Italy 26-28 May 2010

Golding, C., Sharmini, S., Lazarovitch, A.: What examiners do: what thesis students should know. Assess. Eval. High. Educ. 39(5), 563-576 (2014)

James, P.: Progressive development of deep learning skills through undergraduate and postgraduate dissertations. Educ. Stud. 24(1), 95-105 (1998)

Keefe, J.W.: Learning Style: Cognitive and Thinking Skills. National Association of Secondary School Principals, Reston (1991)

Kelleher, C., Wagener, T.: Ten guidelines for effective data visualisation in scientific publications. Environ. Model Softw. 26(6), 822-827 (2011)

Kirschner, P. A., Van Merriënboer, J.: Ten steps to complex learning a new approach to instruction and instructional design. In: Good, T.L. (Ed.), 21st Century Education: A Reference Handbook, Chapter 26, pp. 244-253. Sage, Thousand Oaks (2008)

Koole, M.L.: A model for framing mobile learning. In: Ally, M. (ed.) Mobile Learning: Transforming the Delivery of Education and Training. Athabasca University Press, Edmonton (2009)

Kukulska-Hulme, A.: Mobile learning as a catalyst for change. Open Learn. 25(3), 181-185 (2010)

Larkin, J. H. (1989). What kind of knowledge transfers. Knowing, Learning, and Instruction: Essays in Honor of Robert Glaser. L B Resnikc (Ed.) (pp. 283-305). Chapter 9

Laseau, P.: Graphic thinking for architects and designers. John Wiley \& Sons, New York (2000)

Lave, J., Wenger, E.: Situated Learning: Legitimate Peripheral Participation. Cambridge University Press, Cambridge (1991)

Muller, H., van Biljon, J.A., Renaud, K.V.: Information visualisation in research reporting: guidelines for representing quantitative data. In: Southern African Computer Lecturers' Association, Black Mountain Leisure \& Conference Hotel, Thaba 'Nchu, outside of Bloemfontein, pp. 13-19 (2012)

Mullins, G., Kiley, M.: 'It's a Ph.D., not a Nobel Prize': how experienced examiners assess research theses. Stud. High. Educ. 27(4), 369-386 (2002)

Oh, E., Lim, D.: Cross relationships between cognitive styles and learner variables. J. Interact. Online Learn. Summer 4(1), 53-66 (2005). ISSN: 1541-4914

Petit, L., Santos, G.L.: Mobile Learning: An ergonomic alternative for learning awaited educational changes. In: Mobile as Mainstream-Towards Future Challenges Mobile Learning. 3rd World Conference on Mobile and Contextual Learning, m-Learn, November 3-5, Istanbul, Turkey (2014)

Renkl, A., Atkinson, R.K.: Structuring the transition from example study to problem solving in cognitive skill acquisition: a cognitive load perspective. Educ. Psychol. 38(1), 15-22 (2003)

Robins, A., Rountree, J., Rountree, N.: Learning and teaching programming: a review and discussion. Comput. Sci. Educ. 13(2), 137-172 (2003)

Schaller, R.R.: Moore's law: past, present and future. Spectr. IEEE 34(6), 52-59 (1997) 
Sharples, M., Taylor, J., Vavoula, G.: A theory of learning for the mobile age. In: Medienbildung in neuen Kulturräumen VS Verlag für Sozialwissenschaften. pp. 87-99 (2010)

Sharples, M., Corlett, D., Westmancott, O.: The design and implementation of a mobile learning resource. Pers. Ubiquit. Comput. 6, 220-234 (2002)

Sharples, M., Arnedillo Sánchez, I., Milrad, M., Vavoula, G.: Mobile learning: small devices, big issues. In: Balacheff, N., Ludvigsen, S., de Jong, T., Lazonder, A., Barnes, S. (eds.) Technology Enhanced Learning: Principles and Products Kaleidoscope, pp. 233-249. Springer, Netherlands (2007)

Song, Y.: An authoring and presentation environment for interactive worked examples Ph.D. thesis, University of Glasgow (2014). http://theses.gla.ac.uk/view/creators/Song=3AYulun= $3 \mathrm{~A}=3 \mathrm{~A} \cdot \mathrm{html}$

Traxler, J.: Current State of Mobile Learning. In: Ally, M. (Ed.) Mobile Learning Transforming the Delivery of Education and Training. AU Press, Athabasca University (2009)

Van Biljon, J., Renaud, K.: Do visualisations ease dissertation assessment?. In: Proceedings of the 44th Annual Southern African Computer Lecturers Association 2015 (SACLA), Renewing ICT Teaching And Learning: Building on the Past to Create New Energies, pp 177-185 (2015)

Wishart, J.: Use of mobile technology for teacher training. In: Mobile learning: Transforming the delivery of Education and Training, Ally, M., (Ed.) pp. 265-278 (2009)

Wolfe, R.N., Johnson, S.D.: Personality as a predictor of college performance. Educ. Psychol. Meas. 55, 177-185 (1995)

Zeiller, M.: A case study based approach to knowledge visualisation. In: Information Visualisation, 2005. pp. 377-382. IEEE (2005) 